Article

\title{
Development of Dispersion-Optimized Photonic Crystal Fibers Based on Heavy Metal Oxide Glasses for Broadband Infrared Supercontinuum Generation with Fiber Lasers
}

\author{
Grzegorz Stępniewski ${ }^{1,2}$, Jacek Pniewski ${ }^{1, *(1)}$, Dariusz Pysz ${ }^{2}$, Jarosław Cimek ${ }^{2}$, \\ Ryszard Stępień ${ }^{2}$, Mariusz Klimczak ${ }^{2}$ and Ryszard Buczyński 1,2 (D) \\ 1 Faculty of Physics, University of Warsaw, Pasteura 5, 02-093 Warsaw, Poland; \\ grzegorz.stepniewski@gmail.com (G.S.); Ryszard.Buczynski@fuw.edu.pl (R.B.) \\ 2 Department of Glass, Institute of Electronic Materials Technology, Wólczyńska 133, 01-919 Warsaw, Poland; \\ dariusz.pysz@itme.edu.pl (D.P.); jaroslaw.cimek@itme.edu.pl (J.C.); ryszard.stepien@itme.edu.pl (R.S.); \\ mklimcz@gmail.com (M.K.) \\ * Correspondence: j.pniewski@uw.edu.pl; Tel.: +48-22-55-32-036
}

Received: 31 October 2018; Accepted: 22 November 2018; Published: 25 November 2018

check for updates

\begin{abstract}
In this work a photonic crystal fiber made of a heavy metal oxide glass with optimized dispersion profile is proposed for supercontinuum generation in a broad range of wavelengths in the near-infrared, when pumped by a mode-locked fiber-based laser. The fiber is modelled and optimal geometrical parameters are selected to achieve flat and low dispersion in the anomalous regime. Supercontinuum generation in the range of $0.76-2.40 \mu \mathrm{m}$, within the dynamics of $30 \mathrm{~dB}$, when pumped at $1.56 \mu \mathrm{m}$ with $400 \mathrm{fs}-$ long pulses and an average power $660 \mathrm{~mW}$ is possible. The applicability of such fibers is also discussed.
\end{abstract}

Keywords: photonic crystal fibers; dispersion; supercontinuum generation; soft glass

\section{Introduction}

Interest in photonic crystal fibers (PCFs) has lasted for more than two decades since their invention in 1996 [1]. The possibility of dispersion characteristics' modification by a proper design of the geometrical structure as well as high optical power density in the fiber core led to applications in nonlinear optics [2,3]. Pumping PCFs with high-energy pulses in the anomalous regime of dispersion results in soliton fission that broaden the spectrum of a pulse, due to specific nonlinear phenomena, leading to supercontinuum generation (SG) which can theoretically span several octaves in the frequency domain.

The most popular material of fiber optics, that is fused silica glass, has a relatively low nonlinear refractive index $n_{2}=2.74 \times 10^{-20} \mathrm{~m}^{2} / \mathrm{W}$ at the wavelength of $1053 \mathrm{~nm}$ [4] compared to soft glasses [5] or liquids [6], but its transmission band is limited to approx. $2 \mu \mathrm{m}$. The decrease of transmission in silica glass for longer wavelengths, caused by multi-photon absorption by $\mathrm{Si}-\mathrm{O}$ bondings and vibrational resonances on $\mathrm{OH}$-ions motivates the search for other materials for PCF development that would allow for transmission in mid-infrared (mid-IR). Such transmission is a property of glasses containing heavy atoms with lower excitation energy of optical phonons. A number of these glasses also exhibit higher $n_{2}$ than fused silica. For SG a number of glasses are used, such as fluoride glasses, chalcogenide glasses containing compounds of sulphur, arsenic and selenium [7-9], tellurite glasses [10] and lead oxide glasses $[11,12]$. 
The transmission of ZBLAN glasses ranges up to approximately $5 \mu \mathrm{m}$, what allows for SG in the spectral range of $0.8-4.5 \mu \mathrm{m}[13,14]$, despite relatively low $n_{2}$. These glasses have similar linear and nonlinear refractive index to fused silica glass, but their development requires high quality materials that comes at a high cost of the technological process, including the necessity of isolation from external environment to prevent chemical reaction of fluorine compounds with other compounds in the air, and to prevent pollution because of high toxicity of these substances.

Chalcogenide glasses have the largest $n_{2} \approx 10^{-18} \mathrm{~m}^{2} / \mathrm{W}$, among glasses typically used for drawing of fibers, and the zero dispersion wavelength (ZDW) is located in mid-IR $\left(\lambda_{\mathrm{ZDW}}>4.5 \mu \mathrm{m}\right)$, while the transmission wavelength range extends to over a dozen of micrometers, depending on chemical composition. Pumping of fibers made of these glasses in the anomalous dispersion regime $\left(\lambda_{p}>\lambda_{\text {ZDW }}\right)$ requires advanced mode-locked lasers tuned in the range of 4-7 $\mu \mathrm{m}$. In the paper by Petersen et al. [8] SG in the range of 1.4-13.3 $\mu \mathrm{m}$ was demonstrated in step-index chalcogenide fibers, under pumping with $100 \mathrm{fs}-$ long pulses, centered at a wavelength of $\lambda_{p}=6.3 \mu \mathrm{m}$ and with peak power of $P_{0}=2.3 \mathrm{MW}$, from a complex optical parametric amplifier system.

Zhao et al. also demonstrated mid-IR SG in a low-loss Te-based chalcogenide step-index fiber [15]. The fiber exhibits an optical loss of $2-3 \mathrm{~dB} / \mathrm{m}$ in the range of $6.2-10.3 \mu \mathrm{m}$ and $3.2 \mathrm{~dB} / \mathrm{m}$ at $10.6 \mu \mathrm{m}$. The supercontinuum spectrum was generated in the range of $1.5-14 \mu \mathrm{m}$ when a $23 \mathrm{~cm}-$ long fiber was pumped by a $4.5 \mu \mathrm{m}$ laser with $150 \mathrm{fs}-$ long pulses and the repetition rate $f_{\text {rep }}=1 \mathrm{kHz}$.

Recently, mid-IR SG has been demonstrated in a low-loss telluride glass fiber with a double cladding. The fiber has attenuation lower than $10 \mathrm{~dB} / \mathrm{m}$ in the range of 8-14 $\mu \mathrm{m}$. Ultrashort pulses with a central wavelength of $7 \mu \mathrm{m}$, allowed for SG spanning from $2.0 \mu \mathrm{m}$ to $16 \mu \mathrm{m}$ for a $40-\mathrm{dB}$ spectral flatness [16].

Furthermore, a suspended-core PCF made of tellurite glasses (tellurium oxide glass) has been demonstrated by Domachuk et al. [17] that enable SG in the range of $0.79-4.87 \mu \mathrm{m}$. The core diameter was $2.5 \mu \mathrm{m}$, while $\lambda_{\mathrm{ZDW}}=1.38 \mu \mathrm{m}$. The fiber was pumped using an optical parametric oscillator (OPO) emitting 110 fs-long pulses with $f_{\text {rep }}=80 \mathrm{MHz}$ for $\lambda_{p}=1.55 \mu \mathrm{m}$ and the mean power $P_{\text {avg }}=150 \mathrm{~mW}$. Less than $1 \mathrm{~cm}$ of fiber was used, which was enough to generate hyperspectral supercontinuum at a standard pump wavelength, due to high nonlinearity of the fiber and ultrashort pump pulse duration. It also allowed to broaden the supercontinuum spectrum over $3 \mu \mathrm{m}$ despite usually high absorption of multicomponent oxide glasses at this wavelength due to $\mathrm{OH}$ impurities. On the other hand, telluride glasses are fragile what makes development in the low-cost stack-and-draw process problematic. The suspended core geometry does allow high nonlinearity due to strong confinement, but at the same time it is also strongly isolated thermally from the cladding that leads to a fiber being more susceptible to laser damage, compared to other types of PCFs with low air-glass filling factor.

PCFs made from heavy metal oxide glasses, such as $\mathrm{SF}_{6}$ with $n_{2}=2.2 \times 10^{-19} \mathrm{~m}^{2} / \mathrm{W}$, are an alternative to tellurite glasses. Omenetto et al. [11] demonstrated a fiber with four air-holes surrounding a core of diameter $d_{r}=2.6 \mu \mathrm{m}$, which exhibited $\lambda_{\mathrm{ZDW}}=1.30 \mu \mathrm{m}$. When pumped with an OPO source with $\lambda_{p}=1.55 \mu \mathrm{m}$ SG was achieved in the range of 0.7-3.0 $\mu \mathrm{m}$ with a dynamics of $40 \mathrm{dBs}$.

Other glasses are also used, e.g. bismuth-based glasses. In one of our previous works, we have demonstrated SG in the range of $100-2500 \mathrm{~nm}$ with a $5 \mathrm{~dB}$ flatness in a PCF made of lead-bismuth-gallate glass and pumped in the femtosecond regime at $1540 \mathrm{~nm}$ [18]. Later, a PCF which allowed for SG in the range of 1.2-2.0 $\mu \mathrm{m}$ was shown, when pumped with OPO source with $\lambda_{p}=1.55 \mu \mathrm{m}, 100 \mathrm{fs}-$ long pulses, and $f_{\text {rep }}=1.0 \mathrm{kHz}$ [19]. Finally, spectral and coherence evolution were experimentally measured for SC generated in $\mathrm{PCFs}$ made of $\mathrm{SF}_{6}$ glass [20]. A significant part of our previous work in multi-component oxide soft glass was related to fibers with normal dispersion profiles and a comprehensive review of coherent supercontinuum generation in soft glass photonic crystal fibers can be found in [21]. Table 1 summarizes selected typical properties of glasses used for development of PCFs. 
Table 1. Properties of selected glasses used for development of PCFs [5,13,22-25].

\begin{tabular}{ccccccc}
\hline & Fused Silica & ZBLAN & Chalcogenide & Tellurite & Lead Silicate & PBG81 \\
\hline Linear refractive index $n$ & 1.44 & 1.51 & 2.45 & 2.08 & 1.80 & 1.89 \\
\hline $\begin{array}{c}\text { Nonlinear refractive index } \\
n_{2}\left[10^{-20} \mathrm{~m}^{2} \mathrm{~W}^{-1}\right]\end{array}$ & 4.3 & 2.1 & 250 & 51.1 & $8.9-22$ & 41.3 \\
\hline Transmittance range $[\mu \mathrm{m}]$ & $0.2-2.8$ & $0.2-8$ & $0.9-12$ & $0.5-5$ & $0.4-4.5$ & $0.4-5.5$ \\
\hline $\begin{array}{c}\text { Zero dispersion } \\
\text { wavelength }[\mu \mathrm{m}]\end{array}$ & 1.27 & 1.72 & 4.9 & 2.22 & 1.96 & 2.03 \\
\hline
\end{tabular}

Using OPO sources for SG does not allow for building compact all-fiber systems with broad and high power emission spectrum in the near- and mid-IR, which is important, e.g., in fluorescent microscopy [26], optical coherence tomography [27] and environmental monitoring [28].

In this work we analyze the performance of a PCF made of a heavy metal oxide glass that allows for SG over a full octave under pumping from mode-locked, fiber-based lasers emitting pulses at $1.56 \mu \mathrm{m}$. First, the fiber is modelled and optimal geometrical parameters are selected to achieve flat and low chromatic dispersion in the anomalous regime for spectrally efficient, soliton-based SG. Then, the fiber is developed in the stack-and-draw process and, finally, its nonlinear performance is investigated using SG simulations and physical experiment.

\section{Numerical Simulations of Linear Properties of the PCF}

The analyzed PCF consists of a solid core surrounded by a hexagonal air-hole photonic cladding. Its structure is shown in Figure 1 , where $d_{r}$ denotes the diameter of the core, $d_{1}$ - the diameter of the holes directly surrounding the core in the first row, $d_{2}$-the diameter of the holes in the second row, and $d_{3}$-the diameter of the remaining holes. Due to variable diameters of the holes this structure holds effectively three different filling factors $d / \Lambda$ in the cladding.

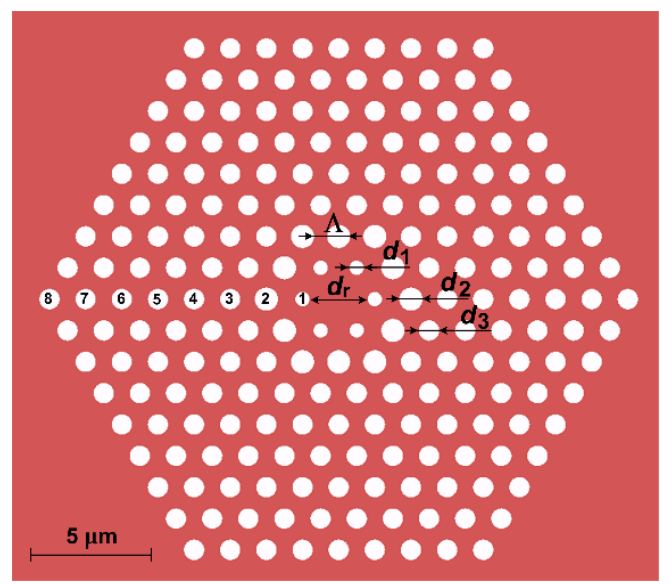

Figure 1. The schematic of the structure of the analyzed PCF. The numbers from 1 to 8 represent subsequent rows of holes surrounding the core.

As a base material for the PCF PBG-08A glass was chosen. This is an in-house developed glass with the chemical composition similar with that of the lead-bismuth-galate PBG-08 glass [18]. The glass was developed under a protective gas atmosphere, what led to the reduction of the water content. As a result, the transmission of the glass was increased in comparison with PBG- 08 to $75 \%$ for the wavelength of $3 \mu \mathrm{m}$. The characteristics of the transmission for both glasses are shown in Figure 2. 


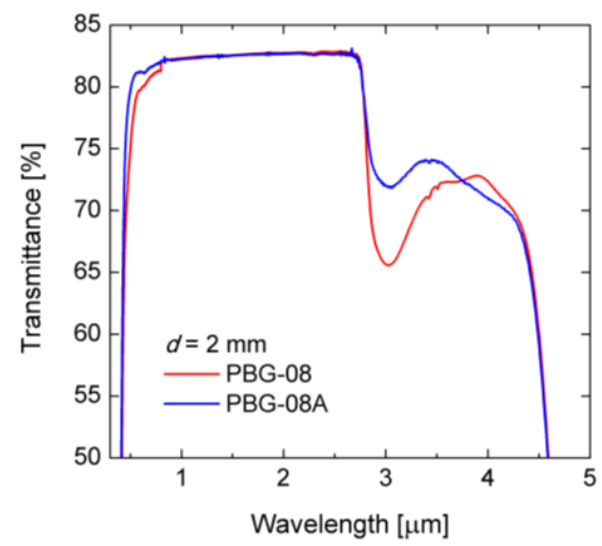

Figure 2. Characteristics of transmission for PBG-08 and PBG-08A glasses, for a 2 mm-thick sample.

The refractive indices of PBG-08 and PBG-08A glass are similar but $n_{\mathrm{PBG}-08 \mathrm{~A}}$ is higher than $n_{\mathrm{PBG}-08}$ by approx. 0.005 . The measurement was done using a Michelson interferometer with the accuracy of 0.002. The refractive index characteristic of PBG-08A glass is modelled using Sellmeier's equation below. The Sellmeier's coefficients calculated on the basis of experimental results are presented in Table 2.

$$
n(\lambda)=\sqrt{1+\frac{B_{1} \lambda^{2}}{\lambda^{2}-C_{1}}+\frac{B_{2} \lambda^{2}}{\lambda^{2}-C_{2}+}+\frac{B_{3} \lambda^{2}}{\lambda^{2}-C_{3}}}
$$

Table 2. Sellmeier's equation coefficients for PBG-08A glass.

\begin{tabular}{cccccc}
\hline $\boldsymbol{B}_{\mathbf{1}}$ & $\boldsymbol{B}_{\mathbf{2}}$ & $\boldsymbol{B}_{3}$ & $\boldsymbol{C}_{\mathbf{1}}$ & $\boldsymbol{C}_{\mathbf{2}}$ & $\boldsymbol{C}_{\mathbf{3}}$ \\
\hline 2.211153 & 0.355174 & 1.16141 & 0.01834 & 0.073012 & 127.3884 \\
\hline
\end{tabular}

The aim of the numerical study was to design a new air-glass structure of a photonic cladding that allows for single mode operation and for flat and low chromatic dispersion in the anomalous regime. We analyzed the influence of the geometrical parameters of the structure, namely the lattice constant $\Lambda$, and diameters of the holes, $d_{1}, d_{2}, d_{3}$, on linear properties of the PCF in terms of effective refractive index $n_{\text {eff }}(\lambda)$, attenuation $A(\lambda)$, and dispersion $D(\lambda)$ for the wavelength range of $0.8-5 \mu \mathrm{m}$. We assumed that the PCF would be coupled to a mode-locked laser emitting at $\lambda_{p}=1.56 \mu \mathrm{m}$, therefore ZDW should be lower than the pump wavelength. A commercial-grade simulator, eigenmode solver and propagator was used to perform the calculations [29].

The possibility of controlling the lattice constant $\Lambda$ and the diameter of air-holes in three subsequent rows allows for precise shaping of dispersion characteristics in a wide range of wavelengths. First, the influence of the lattice constant was simulated for $\Lambda$ in the range of $1.5-2.1 \mu \mathrm{m}$ and two different filling factors in the first and outer rows of holes. The resulting dispersion characteristics of the fundamental mode are shown in Figure 3. The local maximum of the dispersion characteristic in the vicinity of ZDW is the lowest for $\Lambda=1.5 \mu \mathrm{m}$. Thus, this value was used for further analysis.

The subsequent computations were performed for a set of diameters $d_{1}, d_{2}$ and $d_{3}$. Selected dispersion characteristics are shown in Figure 4 . The change of the diameter $d_{1}$ has the biggest influence on the location of ZDW and the shape of the dispersion characteristic in the range of 1.0-5.0 $\mu \mathrm{m}$ (see Figure 4a) [30]. The change of the diameter $d_{2}$ has only small effect on ZDW and influences the dispersion characteristic mainly in the range of $2-4.5 \mu \mathrm{m}$ (see Figure $4 \mathrm{~b}$ ). The change of the diameter $d_{3}$ has almost no effect on ZDW but influences the dispersion characteristic in the range of 2.5-5 $\mathrm{mm}$ (see Figure 4c). Thus, using three different filling factors in the lattice geometry, one has the opportunity to precisely shape the dispersion characteristics, but at the same time even 
small variations in the diameters of the air-holes during fiber development, on the level of tens of nanometers, can lead to a significant change of the characteristics.

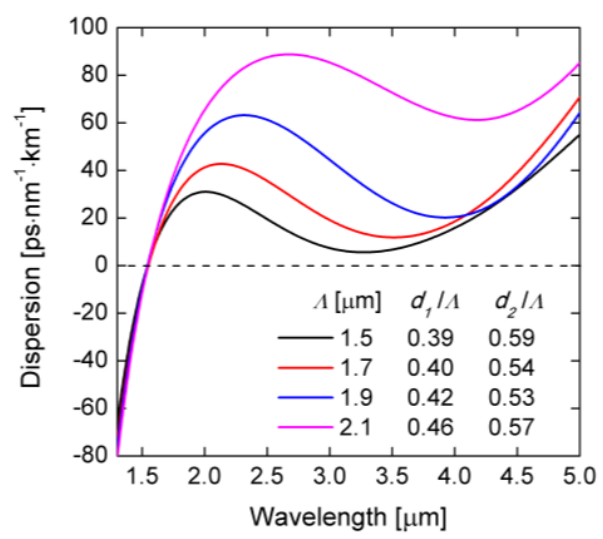

Figure 3. Dispersion characteristics for different lattice constants $\Lambda$ and different filling factors for the first row of air-holes $d_{1} / \Lambda$, and for the other rows of air-holes $d_{2} / \Lambda$.

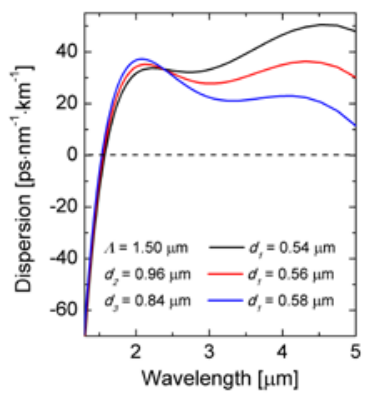

(a)

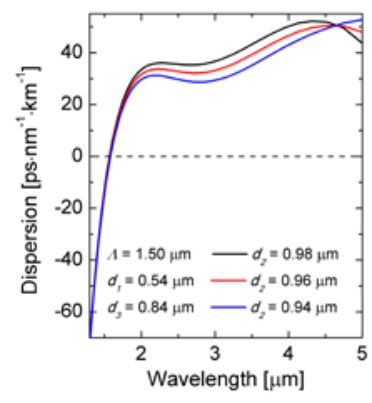

(b)

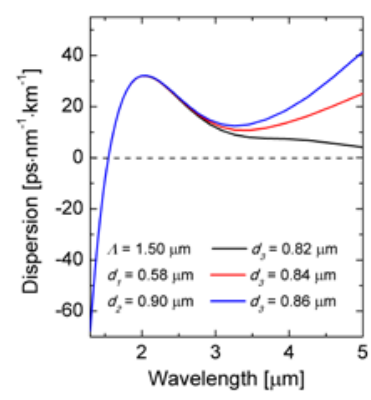

(c)

Figure 4. Dispersion characteristics for the lattice constant $\Lambda=1.5 \mu \mathrm{m}$ and varied diameters of air-holes in (a) the first row $d_{1},(\mathbf{b})$ the second row $d_{2}$, and (c) the other rows of the photonic cladding $d_{3}$.

As a final dispersion-optimized structure the fiber with parameters given in Table 3 was chosen, that exhibits the lowest and flat dispersion in the vicinity of ZDW in the anomalous dispersion regime. The geometrical structure of this PCF is shown in Figure 5. The dispersion characteristics and the effective mode area $A_{\text {eff }}$ are shown in Figure 6. In this fiber ZDW is located at $1.543 \mu \mathrm{m}$ and the maximum dispersion value $D_{\max }=36 \mathrm{ps} /(\mathrm{nm} \cdot \mathrm{km})$ was obtained for the wavelength of $2.106 \mu \mathrm{m}$. For $\lambda_{p}=1.56 \mu \mathrm{m}$ the total fiber dispersion equals $D=2.8 \mathrm{ps} /(\mathrm{nm} \cdot \mathrm{km})$ while the group dispersion equals $\beta_{2}=-3.6 \mathrm{ps}^{2} / \mathrm{km}$ and calculated $A_{\text {eff }}$ is $4.13 \mu \mathrm{m}^{2}$.

Table 3. Geometrical parameters of the dispersion-optimized PCF.

\begin{tabular}{cc}
\hline Parameter & Value \\
\hline$\Lambda$ & $1.50 \mu \mathrm{m}$ \\
$d_{1}$ & $0.57 \mu \mathrm{m}$ \\
$d_{1} / \Lambda$ & 0.38 \\
$d_{2}$ & $0.96 \mu \mathrm{m}$ \\
$d_{2} / \Lambda$ & 0.64 \\
$d_{3}$ & $0.84 \mu \mathrm{m}$ \\
$d_{3} / \Lambda$ & 0.56 \\
$d_{r}$ & $2.43 \mu \mathrm{m}$ \\
\hline
\end{tabular}




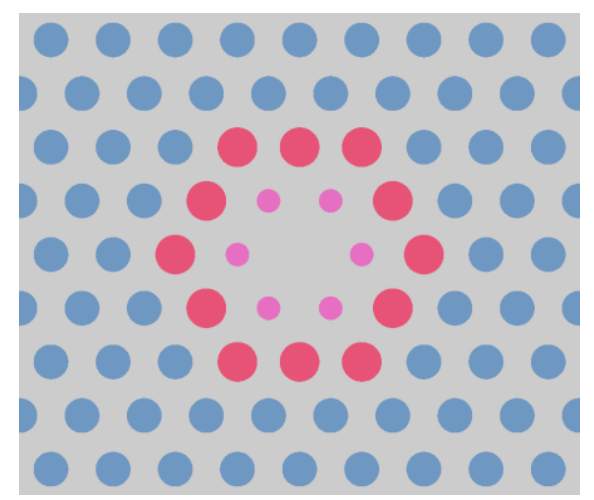

Figure 5. The close-up of the final dispersion-optimized structure. The diameters of the holes are in scale.

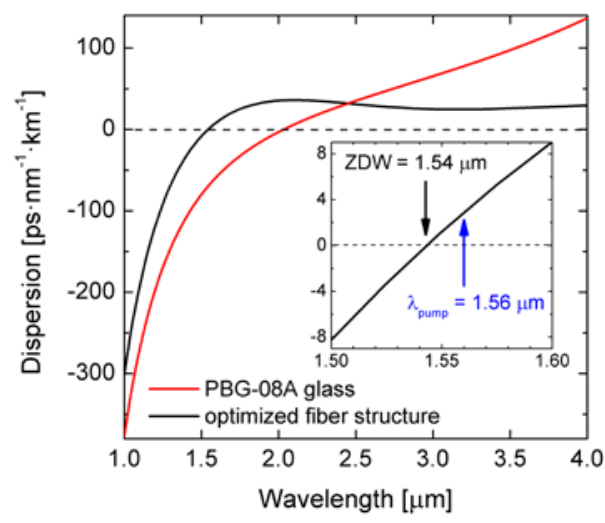

(a)

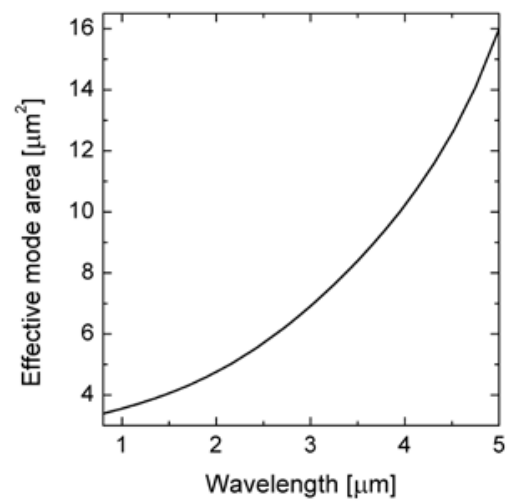

(b)

Figure 6. (a) Optimal dispersion characteristic and (b) effective mode area of the dispersion-optimized PCF.

In the next step, the mode analysis for the dispersion-optimized PCF was performed. Two-dimensional distributions of intensity of the only propagating modes are shown in Figure 7. Additionally, attenuation was computed for the analyzed modes in the range of $0.8-5.0 \mu \mathrm{m}$, shown in Figure 8. As a cut-off attenuation criterion $10 \mathrm{~dB} / \mathrm{m}$ was selected [31]. Therefore, propagation of the mode $\mathrm{LP}_{31}$ is possible, but its attenuation is higher than attenuation of the fundamental mode (FM) by a factor of $10^{9}$. Theoretical cut-off wavelength for the mode $\mathrm{LP}_{31}$ is $2.38 \mu \mathrm{m}$ and for the FM it is $4.0 \mu \mathrm{m}$, which means that the fiber does not guide light in the core for wavelengths longer than $4.0 \mu \mathrm{m}$. Although for the pump wavelength $\Lambda_{p}=1.56 \mu \mathrm{m}$ two modes are guided, the effective coupling efficiency is equal 0.3 for FM and close to zero for the mode $\mathrm{LP}_{31}$, when a Gaussian beam with numerical aperture 0.6 is considered.

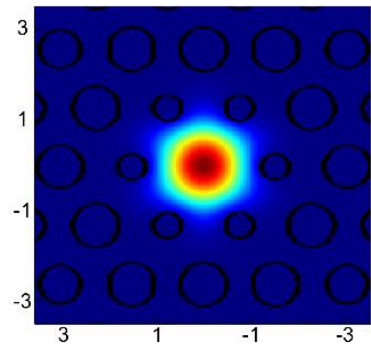

(a)

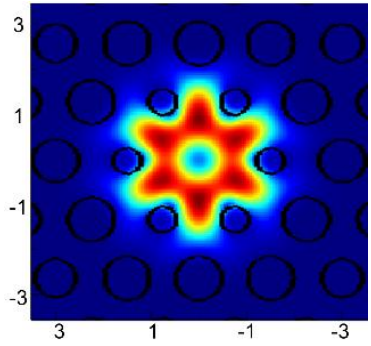

(b)

Figure 7. Numerically simulated distributions of intensity of modes for the wavelength of $1.56 \mu \mathrm{m}$ : (a) fundamental mode $\mathrm{LP}_{01}$, (b) mode $\mathrm{LP}_{31}$. 


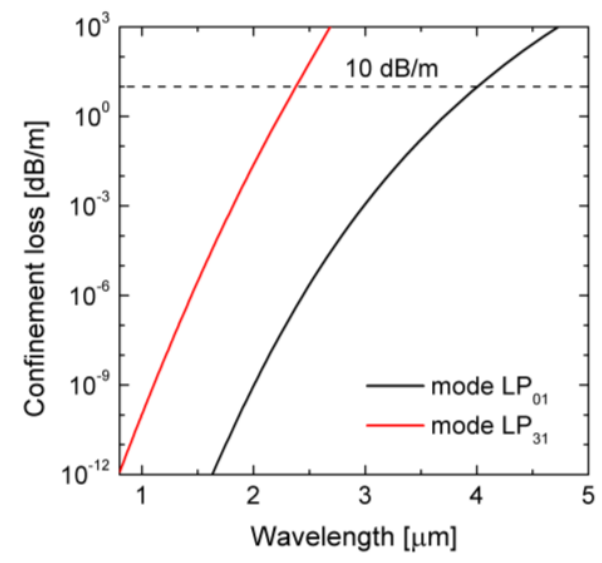

Figure 8. Spectral characteristics of attenuation for propagating modes $\mathrm{LP}_{01}$ and $\mathrm{LP}_{31}$.

\section{PCF Development}

Dispersion-optimized PCFs were then developed in a stack-and-draw process [32]. The drawing process had two stages. First, a subpreform was stacked from capillary tubes and rods and the initial drawing was done with the low pressure to close the gaps between capillaries and rods. Capillaries had different internal diameters for the particular rows of air-holes. Then, the top of the resulting preform was sealed and the final fiber was drawn. The increase of the pressure in the capillaries caused by the increase of the temperature influenced the diameters of the holes. A series of PCFs was drawn, using a prepared subpreform, which differ in size and internal structure. The differences are a result of different drawing speed. The images of the cross-sections of two selected fibers with structures close to the designed one, labeled \#A2 and \#A4, made by a scanning electron microscope, are shown in Figure 9. The geometrical parameters of PCFs are presented in Table 4, where the external diameter of the fiber is denoted as $\varnothing_{\text {out }}$.

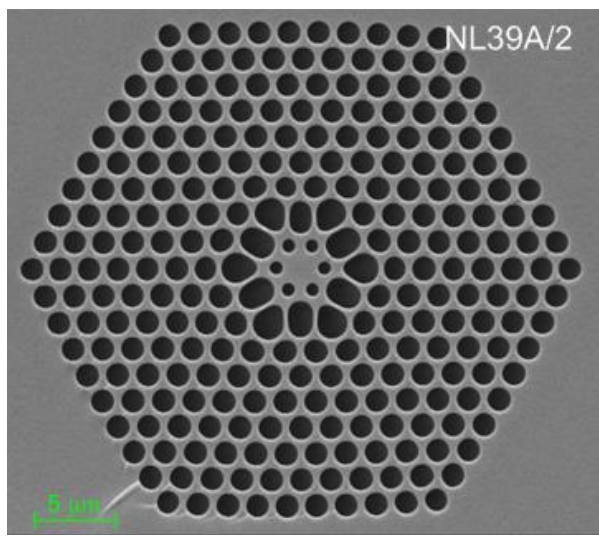

(a)

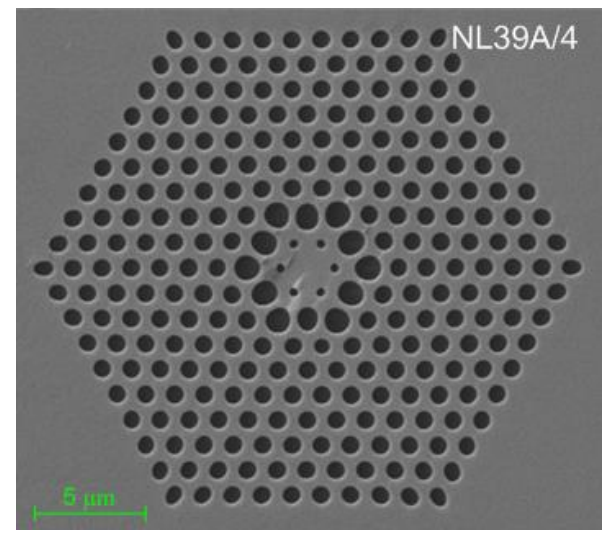

(b)

Figure 9. SEM images of the cross-sections of the developed fibers (a) \#A2 and (b) \#A4.

The structures of PCFs are different from the ideal one but at the same time they are stable over the lengths of single-digit meters, while for SG only tens of centimeters are required. It means that having a certain developed structure its performance is not degraded due to fabrication errors. Stack-and-draw technology does not allow for such precise control of air-hole sizes even if we close the top end of the preform [33,34]. For technological reasons we were not able to use different pressure for subsequent rows of air-holes as suggested in $[35,36]$, but there are a number of factors influencing the final structure, including velocity of drawing, temperature distribution in the furnace, length of the furnace, thickness of the fiber, localization of air-holes in the cladding. Nevertheless, the shape and symmetry of the cladding is maintained. 
Table 4. Geometrical parameters of the selected developed PCFs.

\begin{tabular}{ccc}
\hline & \#A2 & \#A4 \\
\hline$\varnothing_{\text {out }}[\mu \mathrm{m}]$ & 134 & 123 \\
$\Lambda[\mu \mathrm{m}]$ & $\sim 1.8$ & $\sim 1.3$ \\
$d_{1}[\mu \mathrm{m}]$ & 0.73 & 0.38 \\
$d_{2}[\mu \mathrm{m}]$ & $2.00 \times 1.35$ & $1.19 \times 1.03$ \\
$d_{3}[\mu \mathrm{m}]$ & 1.43 & 0.83 \\
$d_{1} / \Lambda$ & 0.52 & 0.32 \\
$d_{2} / \Lambda$ & 0.74 & 0.75 \\
$d_{3} / \Lambda$ & 0.80 & 0.64 \\
$d_{r}[\mu \mathrm{m}]$ & 2.13 & 2.06 \\
cladding size $[\mu \mathrm{m}]$ & $33.5 \times 29.5$ & $24.5 \times 20.9$ \\
\hline
\end{tabular}

The air-holes in the second row are deformed and have oval or elliptical shape. The lattice constant is not preserved in the whole cladding and is reduced in the first ring of holes due to large diameter of the air-holes in the second row. For the fiber \#A2 the lattice constant decreases from approx. $1.8 \mu \mathrm{m}$ to $1.4 \mu \mathrm{m}$, while for the fiber \#A4 from approx. $1.3 \mu \mathrm{m}$ to $1.2 \mu \mathrm{m}$. The fiber \#A2 has significantly bigger filling factor in the rows from 2 to 9 than in case of the designed structure. This discrepancy is decreased in the fiber \#A4 through the reduction of the diameters of the air-holes that, in turn, led to the decrease of the diameters of the air-holes surrounding the core.

\section{Characterization of Linear Properties of Developed PCFs}

The developed fibers were characterized with respect to linear optical properties, namely mode structure, attenuation, numerical aperture (NA) and chromatic dispersion. The modes were determined at the wavelength of $1.56 \mu \mathrm{m}$ using an amplified spontaneous emission source (ASE), capable to emit spatially coherent light in the range of 1.51-1.62 $\mu \mathrm{m}$. The output plane of the PCF was imaged on a phosphorus-enriched CCD camera using a microscopic objective $60 \times / 0.85$, what allowed to record IR images in the range of $1.46-1.60 \mu \mathrm{m}$.

A change of the position of the fiber with respect to the focus of the light-introducing lens was applied to excite the fundamental and higher order modes. The measurement was performed for both long (more than $2 \mathrm{~m}$ ) and short $(40-50 \mathrm{~cm})$ sections of the fibers. For long sections only fundamental mode was observed.

The attenuation was measured using the cut-back method. The resulting attenuation characteristics are shown in Figure 10. The characteristics are typical for the PBG glasses with the increase below $1.30 \mu \mathrm{m}$ and the peak of $7-10 \mathrm{~dB} / \mathrm{m}$ around $1.55 \mu \mathrm{m}$. For $\lambda_{p}=1.56 \mu \mathrm{m}$ the attenuation reaches $6.3 \mathrm{~dB} / \mathrm{m}$ and $7.7 \mathrm{~dB} / \mathrm{m}$ for the fibers \#A2 and \#A4, respectively. Higher attenuation of the fiber \#A4 compared to \#A2 results from higher confinement losses and fabrication imperfections. The latter causes an emission of light to the photonic cladding and outer glass layer through micro-ruptures that are common in soft glasses.

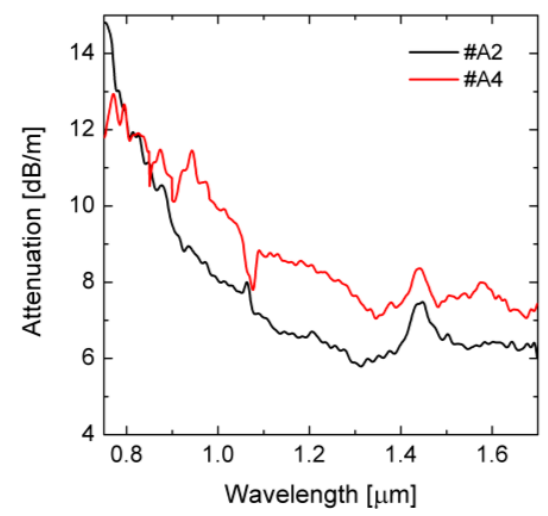

Figure 10. Measured attenuation characteristics for the fibers \#A2 and \#A4. 
The numerical apertures of the fibers \#A2 and \#A4 were measured with ASE source with central wavelength of $1.56 \mu \mathrm{m}$ using the CCD camera and under the assumption that the beam is Gaussian with the waist located at the end of the fiber. For the fiber \#A2 NA $=0.52$, while for the fiber \#A4 $\mathrm{NA}=0.51$.

The chromatic dispersion was both numerically modelled and experimentally measured. Simulations were performed on the basis of SEM images of the fibers, while for the measurement we used a Mach-Zehnder interferometer [37]. The resulting dispersion characteristics are shown in Figure 11 and the values of ZDW and the dispersion $D_{p}$ for pumping at $\lambda_{p}=1.56 \mu \mathrm{m}$ are presented in Table 5. The dispersion of the fiber \#A2 for $\lambda_{p}$ is located in the anomalous regime. In case of the fiber \#A4 ZDW is located close to $\lambda_{p}$ and actually the fiber can be excited in the normal or anomalous regime.

Measured and predicted in numerical simulations chromatic dispersion characteristics do not overlap, although the overall tendency is maintained. Measured values are shifted towards shorter wavelengths. In case of the fiber \#A4 the wavelength difference equals $189 \mu \mathrm{m}$. There are a number of factors influencing the outcome of the numerical simulations. First, the procedure of binarization of the SEM image may not be accurate and, thus, change the diameters of the air-holes. Second, the structure of the PCF along the fiber is not perfectly maintained. As a result, the actually measured fiber can be different from the fiber imaged by SEM. Third, the accuracy of the Mach-Zehnder interferometer is limited to single-digit nanometers.

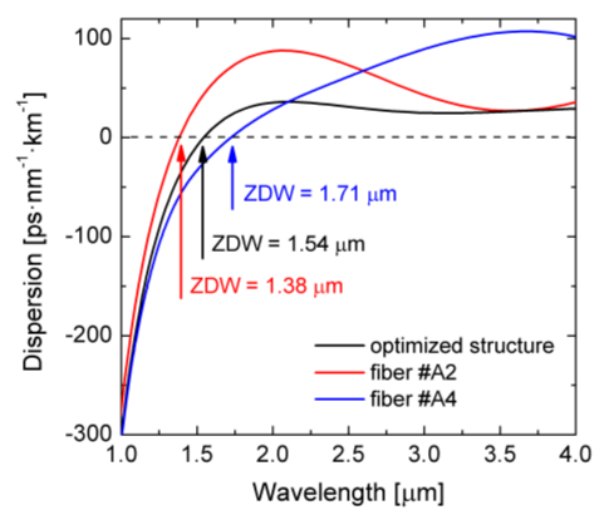

(a)

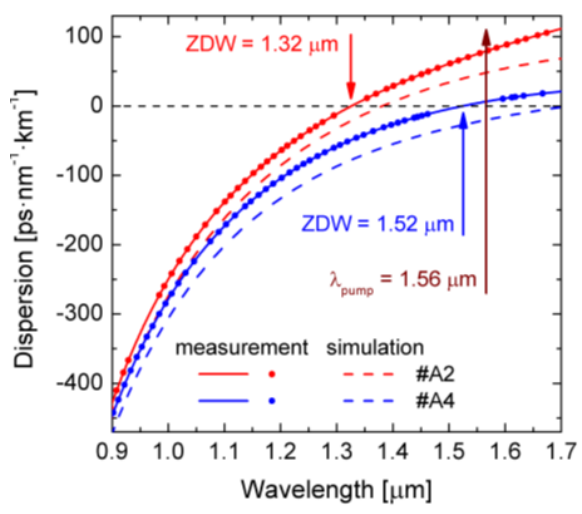

(b)

Figure 11. Dispersion characteristics of the fibers (a) \#A2 and \#A4 (simulation) compared to the dispersion characteristic of the ideal dispersion-optimized structure, (b) A2 and \#A4 (both simulated and measured).

The effective mode are was modelled on the basis of SEM images. For the fiber \#A2 $A_{\text {eff }}=3.11 \mu \mathrm{m}^{2}$, while for the fiber \#A4 $A_{\text {eff }}=3.70 \mu \mathrm{m}^{2}$.

Table 5. Measured ZDWs and dispersion values at intended pump wavelength for the fibers \#A2 and \#A4.

\begin{tabular}{ccc}
\hline & \#A2 & \#A4 \\
\hline$\lambda_{\text {ZDW }}[\mu \mathrm{m}]$ & 1.326 & 1.525 \\
$D_{p} @ 1.56 \mu \mathrm{m}[\mathrm{ps} /(\mathrm{nm} \cdot \mathrm{km})]$ & 77.6 & 5.4 \\
\hline
\end{tabular}

\section{Supercontinuum Generation in Developed PCFs}

Simulations of SG were performed for both the dispersion-optimized ideal structure and the developed fibers \#A2 and \#A4. Generalized nonlinear Schrödinger equation (GNLSE) was solved 
numerically to simulate the pump pulse propagation, and specifically the split-step Fourier algorithm was implemented [38,39]. In the GNLSE of the form of:

$$
\frac{\partial A}{\partial z}+\frac{\alpha}{2} A-\sum_{k \geq 2} \frac{i^{k+1}}{k !} \beta_{k} \frac{\partial^{k} A}{\partial T_{k}}=i \gamma\left(1+i \tau_{\text {shock }} \frac{\partial}{\partial T}\right): \times\left(A(z, T) \int_{-\infty}^{+\infty} R\left(T^{\prime}\right)\left|A\left(z, T-T^{\prime}\right)^{2}\right| d T^{\prime}\right)
$$

where $A$ represents the complex pulse envelope, $z$ is the coordinate along the fiber (propagation) length, and the left-hand side describes linear processes, while the right-hand side describes the nonlinear processes. The second term in the left-hand side accounts for a linear loss with loss coefficient $\alpha$, and the third term represents the dispersion with the dispersion coefficient $\beta_{k}$ associated with Taylor series expansion of the propagation constant $\beta(\omega)$ about central frequency $\omega_{0}$. At the right-hand side, the nonlinear coefficient is given by $\gamma=\mathrm{n}_{2} \cdot \omega_{0} /\left(c \cdot A_{\text {eff }}\right)$, where $n_{2}=2 \times 10^{-19} \mathrm{~m}^{2} / \mathrm{W}$ is the nonlinear refractive index of the fiber glass, here measured using z-scan at $1064 \mathrm{~nm}$ [5], the Raman response of glass is parametrized analogically to [38,39], and specifically the first order Raman shift frequency for the fiber glass in this work is $\Omega_{R}= \pm 29 \mathrm{THz}$, and the Lorentzian fit to the first-order Raman scattering term is described by time-frequency of excited optical fonons $\tau_{1}=5.5 \mathrm{fs}$, and time-width of Lorentz band $\tau_{2}=32 \mathrm{fs}$. The contribution of delayed Raman scattering response to the Kerr nonlinearity was $f_{R}=0.05$. The simulation time window corresponded in the spectral domain to the wavelength range of $0.8-5.0 \mu \mathrm{m}$. The pump pulse duration (auto-correlation width) was $t_{i m p}=400 \mathrm{fs}$.

In Figure 12 supercontinuum pulse spectra simulated for the ideal dispersion-optimized PCF are shown for the wavelength range of $0.8-5.0 \mu \mathrm{m}$, for different input pulse energies. The length of the fiber is $5 \mathrm{~cm}$. For the pulse energy $E_{i m p}=0.8 \mathrm{~nJ}$ the broadening dynamics are limited practically to self-phase modulation (SPM) within a wavelength span of approximately $400 \mathrm{~nm}$ and within $20 \mathrm{~dB}$ dynamic range. Increasing $E_{i m p}$ to more than $1 \mathrm{~nJ}$ results in further spectrum broadening, and for $E_{i m p}=2.4 \mathrm{~nJ}$ supercontinuum goes up to $3.6 \mu \mathrm{m}$ in IR within $20 \mathrm{~dB}$ dynamics. In Table 6 dispersion lengthscale $L_{D}$, nonlinear lengthscale $L_{N L}$, and soliton fission lengthscale $L_{s o l}$ for $N$-order solitons are summarized, for the pulse energy $E_{i m p}=2.4 \mathrm{~nJ}$. The dispersion lengthscale is expressed as $L_{D}=t_{0}{ }^{2} /\left|\beta_{2}\right|$, while the other lengthscales are defined as $L_{N L}=1 / \gamma P_{0}$ (where $P_{0}$ is the peak pump power), $L_{s o l}=L_{D} / N$, and the soliton order is expressed as $N=L_{D} / L_{N L}$.

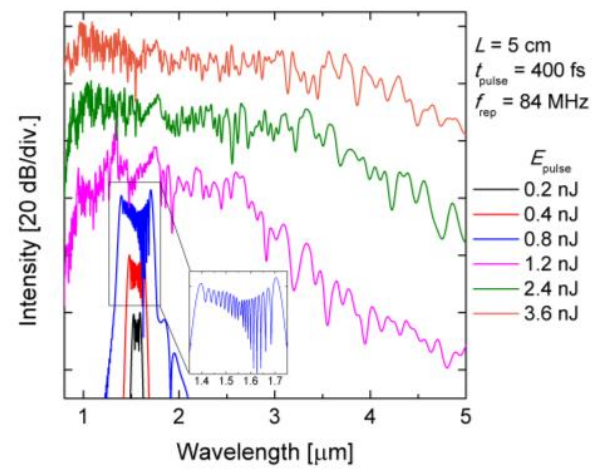

Figure 12. Numerical simulation of SG in the dispersion-optimized PCF, for pulse energy in the range of 0.2-3.6 nJ. For clarity characteristics are separated vertically by $20 \mathrm{~dB}$.

Table 6. Parameters of SG for the dispersion-optimized PCF.

\begin{tabular}{cccc}
\hline$L_{D}[\mathrm{~m}]$ & $L_{N L}[\mathrm{~mm}]$ & $L_{\text {sol }}[\mathrm{mm}]$ & $N$ \\
\hline 44.4 & 0.39 & 133 & 334 \\
\hline
\end{tabular}

The evolution of the pulse as a function of the propagation length is shown in Figure 13a, while the calculated group delay trace (spectrogram) is shown in Figure 13b, for $E_{i m p}=2.4 \mathrm{~nJ}$ and $L=5 \mathrm{~cm}$. At the beginning of the fiber, the spectrum of the pulses expands due to SPM. This is expected, because $L_{N L}$ is 
larger than $L_{D}$, therefore SG occurs with dominance of nonlinear contribution over dispersion. Around $2 \mathrm{~cm}$ of propagation, the high order input soliton has already undergone fission into multiple low order solitons, which is in rough agreement with the $1.3 \mathrm{~cm}$ value estimated using formula $L_{\text {sol }}=L_{D} / N$. Due to high order $N=334$ of the soliton introduced by the pump, the supercontinuum is expected to be time-incoherent, despite femtosecond pumping [40]. The modulation instability lengthscale can be estimated as $16 \cdot L_{N L}$, which in this case is just over $6 \mathrm{~cm}$. This result provides rationale for assuming the fiber length of $5 \mathrm{~cm}$, in order to observe supercontinuum generation before amplification of significant noise. Soliton fission and their subsequent Raman redshift is accompanied by a radiation of higher frequencies, the dispersive waves, which is responsible for broadening of the supercontinuum spectrum towards shorter wavelengths. As a result of the decay the lower-order solitons are shifted towards IR due to Raman scattering (SSFS, soliton self-frequency shift). Because of relatively low anomalous chromatic dispersion at wavelengths redshifted from ZDW (0-36 ps/(nm· $\mathrm{km}))$ broad phase matching can be achieved in the range of $1-4 \mu \mathrm{m}$ for the degenerated four-wave mixing.

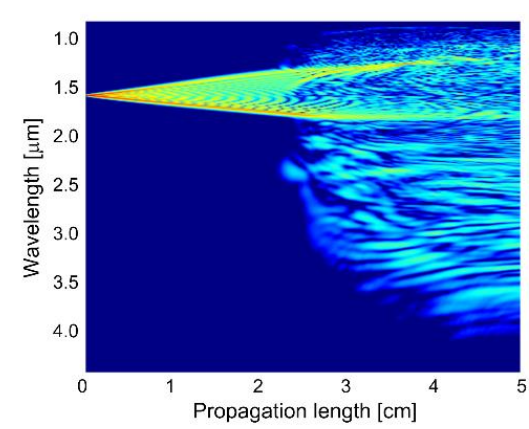

(a)

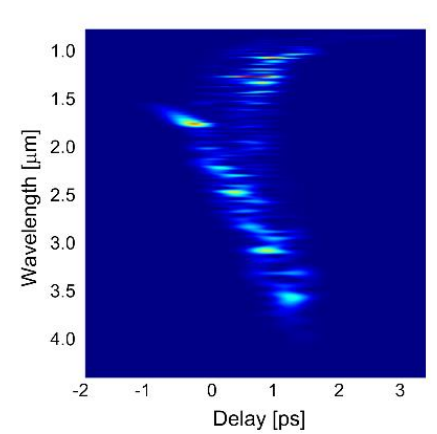

(b)

Figure 13. (a) Evolution of the pulse and (b) spectrogram for the dispersion-optimized PCF.

In the next step, nonlinear propagation simulations were conducted using fiber linear properties data calculated for real fiber structures using SEM images of the fibers \#A2 and \#A4. The results are shown in Figure 14, while in Table 7 nonlinear parameters are shown, namely group velocity dispersion $\beta_{2}$, third-order dispersion $\beta_{3}$, nonlinear coefficient $\gamma$, dispersion length $L_{D}$, nonlinear length $L_{N L}$, soliton decay length $L_{s o l}$, order of solitons $N$, for $\lambda_{p}=1.56 \mu \mathrm{m}$ and $E_{i m p}=2.4 \mathrm{~nJ}$.

In the nonlinear propagation simulations for the fiber \#A2, it is assumed that pumping falls into wavelengths, where there is anomalous chromatic dispersion. Results of simulations are summarized in Figure 14a-c. High nonlinearity results in pulse nonlinear lengthscale of $L_{N L}=0.3 \mathrm{~mm}$, however $L_{D}$ is also short, one order of magnitude larger than $L_{N L}$, as opposed to two orders of magnitude in the ideal fiber. First $1 \mathrm{~cm}$ of propagation is dominated by SPM, which is followed by soliton fission and Raman redshift, accompanied by dispersive wave generation. Calculated soliton order is over three times smaller, than in the fiber considered in the design stage, thus the group delay trace shows several discernible soliton features between around 0.5 and 4 ps of delay (Figure 14c). Due to very short nonlinear length scale, the estimated modulation instability lengthscale is just below $5 \mathrm{~cm}$, suggesting onset of noise amplification and decoherence of supercontinuum pulses over the final $2 \mathrm{~mm}$ of the fiber. The width of the spectrum is $0.8-3.7 \mu \mathrm{m}$ within $20 \mathrm{~dB}$ dynamics.

In the nonlinear propagation simulations for the fiber \#A4, the $\lambda_{Z D W}>\lambda_{p}$ and the pump pulse is introduced at wavelengths with normal dispersion regime. The broadening is again initiated by SPM, because $L_{N L}$ is still roughly 20 times shorter than $L_{D}$. When the redshifted part of SPM reaches and crosses ZDW at $1.714 \mu \mathrm{m}$, solitons begin to emerge at anomalous dispersion wavelengths. Their redshift is faintly visible in the group delay trace in Figure 14f just before end of $5 \mathrm{~cm}$ of propagation. In this scenario, the redshifting solitons also generate dispersive waves across ZDW, which here result in destructive beating with the normal dispersion-broadened spectral components, giving rise to complicated spectral evolution both in the group delay (Figure 14f) and along the fiber length (Figure 14e). The supercontinuum spectrum covers 1.0-2.9 $\mu \mathrm{m}$. 


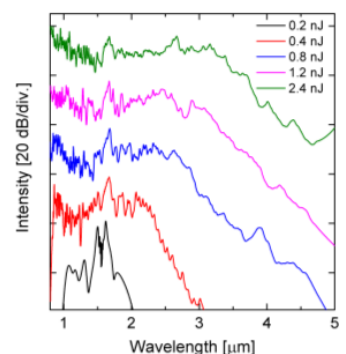

(a)

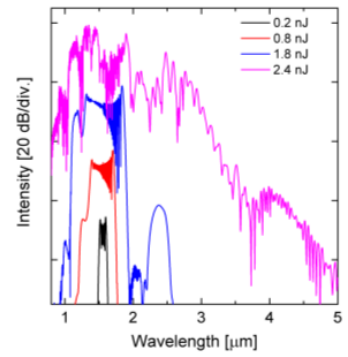

(d)

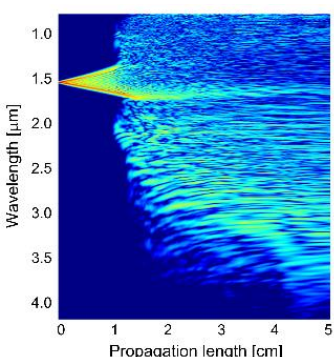

(b)

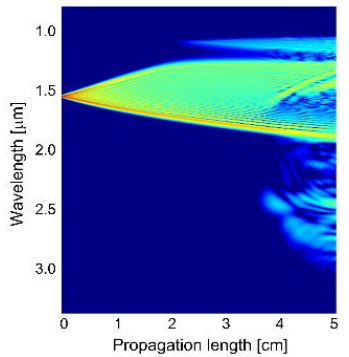

(e)

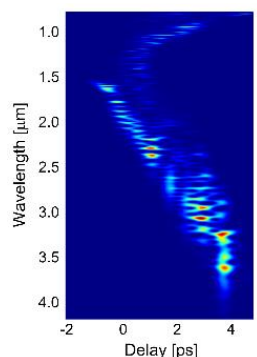

(c)

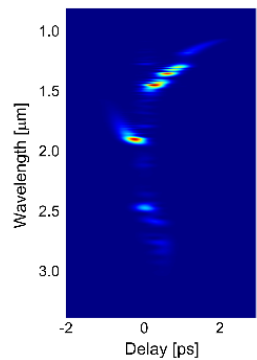

(f)

Figure 14. Numerically generated (a,d) supercontinuum spectra for in the range of 0.2-2.4 nJ, $(\mathbf{b}, \mathbf{e})$ evolution of the spectra as a function of the length of the fiber for $E_{i m p}=2.4 \mathrm{~nJ},(\mathbf{c}, \mathbf{f})$ time-delay spectrograms. The upper rower depicts the fiber \#A2, while lower-\#A4.

Table 7. Nonlinear parameters for computer simulations in the fibers \#A2 and \#A4.

\begin{tabular}{cccccccc}
\hline & $\begin{array}{c}\beta_{2} \\
{\left[\mathbf{p s}^{2} / \mathbf{k m}\right]}\end{array}$ & $\begin{array}{c}\beta_{3} \\
{\left[\mathbf{p s}^{3} / \mathbf{k m}\right]}\end{array}$ & $\begin{array}{c}\gamma \\
{\left[\mathbf{k m}^{-1} \mathbf{W}^{-1}\right]}\end{array}$ & $\begin{array}{c}\mathbf{L}_{\mathbf{D}} \\
{[\mathbf{m}]}\end{array}$ & $\begin{array}{c}\boldsymbol{L}_{N L} \\
{[\mathbf{m m}]}\end{array}$ & $\begin{array}{c}\boldsymbol{L}_{\text {sol }} \\
{[\mathbf{m m}]}\end{array}$ & $N$ \\
\hline \#A2 & -61.5 & 0.42 & 557 & 2.6 & 0.30 & 27.9 & 93 \\
\#A4 & 25.1 & 0.23 & 468 & 6.4 & 0.36 & 47.6 & 134 \\
\hline
\end{tabular}

For the coupling of pump laser light to the fibers in the experimental part of work, two microscopic objectives $40 \times / 0.65$ were used. At the output, the collimated beam was focused on a front face of a multi-mode fiber, using an achromatic lens with $f=50 \mathrm{~mm}$. The multi-mode fiber was connected to an optical spectrum analyzer (OSA). Two OSAs were used, both from Yokogawa, one device covered spectral range of 0.6-1.7 $\mu \mathrm{m}$ and the other of 1.2-2.4 $\mu \mathrm{m}$. The length of both nonlinear PCFs (\#A2 and \#A4) was $L=15 \mathrm{~cm}$ and the coupling efficiency was estimated at $15 \%$. The length of the fiber samples was motivated with handling convenience. The broadening of the spectrum as a function of average power $P_{\text {avg }}$ of the laser source is shown in Figure 15.

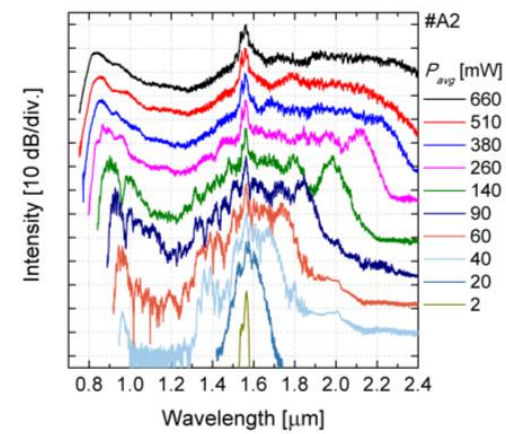

(a)

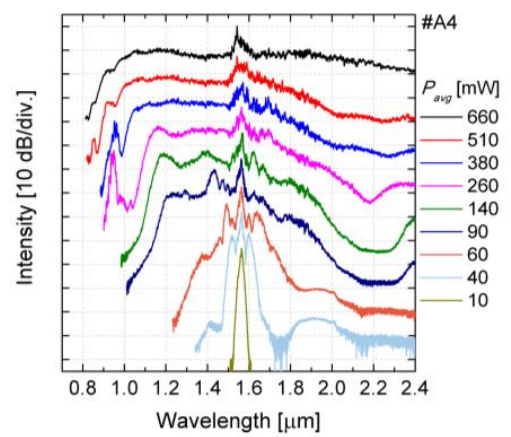

(b)

Figure 15. Measured supercontinuum spectra for the fibers (a) \#A2 and (b) \#A4 for different average power of the pumping laser. For clarity characteristics are separated vertically by $20 \mathrm{~dB}$. 
Taking into account the coupling efficiency approx. $P_{\text {avg }}=100 \mathrm{~mW}$ was obtained, which corresponded to peak power of $P_{0}=2.95 \mathrm{~kW}$ and coupled pulse energy of $E_{i m p}=1.18 \mathrm{~nJ}$. In the physical experiments with the fiber \#A2, pumping is in the anomalous dispersion wavelengths, and the spectrum is efficiently broadened towards the short-wave range. For $P_{\text {avg }}=60 \mathrm{~mW}\left(E_{\text {imp }}=0.11 \mathrm{~nJ}\right)$ a peak appears for the wavelength of $0.96 \mu \mathrm{m}$ caused by the dispersive wave caused by the soliton decay in the long-wavelength range. At this pump power the spectrum is still non-uniform and exhibits a decrease of the intensity in the range of 0.96-1.4 $\mu \mathrm{m}$ along with the spectrum limit at $1.80 \mu \mathrm{m}$. The increase of the pump power results in the broadening of the spectrum towards IR. For wavelengths shorter than $\lambda_{p}$ the spectrum becomes smooth and flat and the short-wavelength limit is shifted towards visible wavelengths but slower than long-wavelength limit. For $P_{\text {avg }}=660 \mathrm{~mW}$ $\left(E_{i m p}=1.18 \mathrm{~nJ}\right)$ the spectrum still shows a clearly pronounced dispersive wave separated by a slightly less intense plateau in the range of $0.84-1.51 \mu \mathrm{m}$ wavelengths. For the dynamic range of $30 \mathrm{~dB}$ the spectral coverage of SG in fiber \#A2 is not less than 0.76-2.4 $\mu \mathrm{m}$ wavelengths, since the detection limit of OSA was $2.4 \mu \mathrm{m}$.

The fiber \#A4 is pumped very close to the ZDW, and part of the pump pulse spectrum falls into normal dispersion wavelengths, while part of the pulse spectrum covers anomalous dispersion wavelengths of the fiber. For average power of $P_{a v g}=60 \mathrm{~mW}$ the pulse is broadened only due to SPM and its width is equal to $0.41 \mu \mathrm{m}(1.35-1.76 \mu \mathrm{m})$ within $30 \mathrm{~dB}$ dynamics. The increase of the power of the laser in the range of $90-510 \mathrm{~mW}$ broadens the flat supercontinuum spectrum in the short-wavelength range. For waves longer than $1.56 \mu \mathrm{m}$ the intensity decreases with the wavelength. Starting from $P_{\text {avg }}=260 \mathrm{~mW}$ a blue-shifted peak appears in the spectrum at about $0.9 \mu \mathrm{m}$ that is assigned to a dispersive wave related to a soliton, which emerges at the anomalous dispersion side of the ZDW, where enough energy is transferred over to the anomalous dispersion wavelength range of fiber. For the maximum available pump power, the supercontinuum covers wavelength range of $0.86-2.4 \mu \mathrm{m}$ (measurement limited by OSA sensitivity range). This less reach in terms of blue-shifted wavelength than the width for the fiber \#A2, but at the same time the spectrum is flatter than in the case of \#A2 fiber.

In Figure 16 the characteristics of supercontinuum spectrum are compared, for the fibers \#A2 and \#A4, for $P_{\text {avg }}=660 \mathrm{~mW}$. The width of supercontinuum spectra, for different dynamics and the length of the fibers $15 \mathrm{~cm}$, are shown in Table 8 .

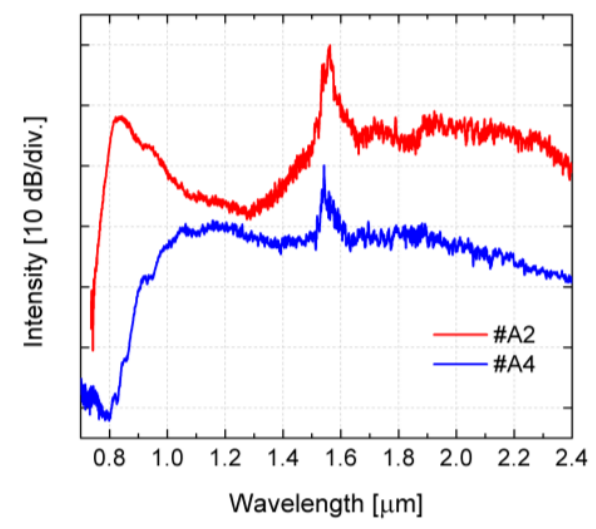

Figure 16. Measured supercontinuum spectra for the fibers \#A2 and \#A4 and $P_{a v g}=660 \mathrm{~mW}$. For clarity characteristics are separated vertically by $20 \mathrm{~dB}$.

Table 8. Width of the supercontinuum spectrum for the fibers \#A2 and \#A4.

\begin{tabular}{ccccccc}
\hline & \multicolumn{3}{c}{ Dynamics 20 dB } & \multicolumn{3}{c}{ Dynamics 30 dB } \\
\hline & $\lambda_{\min }[\mu \mathrm{m}]$ & $\lambda_{\max }[\mu \mathrm{m}]$ & $\Delta \lambda[\mu \mathrm{m}]$ & $\lambda_{\min }[\mu \mathrm{m}]$ & $\lambda_{\max }[\mu \mathrm{m}]$ & $\Delta \lambda[\mu \mathrm{m}]$ \\
\hline \#A2 & 1.45 & 2.40 & 0.95 & 0.76 & 2.40 & 1.64 \\
\#A4 & 0.90 & 2.40 & 1.50 & 0.86 & 2.40 & 1.54 \\
\hline
\end{tabular}




\section{Conclusions}

In the paper the possibility to shape the dispersion characteristics of a PCF due to a precise choice of the diameters of the air-holes in the cladding, including variable filling factor, was demonstrated in the fiber made of a heavy metal oxide glass PBG-08A. The influence of certain rows of holes surrounding the core on the dispersion characteristics was determined. Then, a proof-of-concept was shown, including two physically developed fibers with designed parameters, developed in the stack-and-draw process. It was proven, both in simulations and experimentally, that supercontinuum generation over broad wavelength range in the near-IR with this PCF is possible, when the fibers are pumped with a standard fiber-based laser wavelength of $1.56 \mu \mathrm{m}$ with $400 \mathrm{fs}-$ long pulses with an average power $660 \mathrm{~mW}$.

The presented PCF is well suited to all-fiber systems, and does not require OPO for pumping. The proof-of-concept also evidenced that good control of the technological development process is crucial for the repeatability of the fiber's structure. Using variable filling factor in the lattice geometry of the photonic cladding allows for dispersion engineering in a broad range, but at the same time a small change of a diameter of air-holes in one row influences the lattice constant, the filling factor, and the shape of holes in neighboring rows. The technological part of work revealed, that it is challenging to maintain the variable filling factor geometry during fiber drawing, when a demanding soft glass is used, although the developed structure is stable over the lengths of single-digit meters, while for supercontinuum generation only tens of centimeters are required. In the results reported herein, the agreement between the properties of fibers designed and of fibers actually drawn was unsatisfactory. Hence, additional methods of fiber structure control, e.g., variable pressure applied to the individual holes of the preform [33-36], should be considered.

Author Contributions: Conceptualization, M.K. and R.B.; methodology, G.S. and J.P.; software, G.S., J.P. and M.K.; formal analysis, G.S., J.P., M.K. and R.B.; investigation, G.S., J.P. and M.K.; resources, G.S., D.P., J.C. and R.S.; data curation, G.S. and J.P.; writing-original draft preparation, G.S., J.P., M.K. and R.B.; visualization, G.S., J.P. and M.K.; supervision, J.P., M.K. and R.B.; project administration, G.S and R.B.; funding acquisition, J.P, M.K. and R.B.

Funding: This work was supported by the project First TEAM/2016-1/1 operated within the Foundation for Polish Science Team Programme co-financed by the European Union under the European Regional Development Fund, European Training Network H2020-MSCA-ITN-2016 Grant No 722380, SUPUVIR: Supercontinuum broadband light sources covering UV to IR applications and National Science Centre, Poland grant 2016/22/M/ST2/00261. J.P. was also supported by the statutory fund, financed by the Faculty of Physics at the University of Warsaw.

Conflicts of Interest: The authors declare no conflict of interest.

\section{References}

1. Knight, J.C.; Birks, T.A.; Russell, P.S.J.; Atkin, D.M. All-silica single-mode optical fiber with photonic crystal cladding. Opt. Lett. 1996, 21, 1547. [CrossRef] [PubMed]

2. Ranka, J.K.; Windeler, R.S.; Stentz, A.J. Visible continuum generation in air-silica microstructure optical fibers with anomalous dispersion at $800 \mathrm{~nm}$. Opt. Lett. 2000, 25, 25. [CrossRef] [PubMed]

3. Buczyński, R.; Pniewski, J.; Pysz, D.; Stępień, R.; Kasztelanic, R.; Kujawa, I.; Filipkowski, A.; Waddie, A.; Taghizadeh, M. Dispersion management in soft glass all-solid photonic crystal fibres. Opto-Electron. Rev. 2012, 20. [CrossRef]

4. Milam, D. Review and assessment of measured values of the nonlinear refractive-index coefficient of fused silica. Appl. Opt. 1998, 37, 546. [CrossRef] [PubMed]

5. Cimek, J.; Liaros, N.; Couris, S.; Stępień, R.; Klimczak, M.; Buczyński, R. Experimental investigation of the nonlinear refractive index of various soft glasses dedicated for development of nonlinear photonic crystal fibers. Opt. Mater. Express 2017, 7, 3471. [CrossRef]

6. Zhao, P.; Reichert, M.; Ensley, T.R.; Shensky, W.M.; Mott, A.G.; Hagan, D.J.; Stryland, E.W.V. Nonlinear refraction dynamics of solvents and gases. Proc. SPIE 2016, 9731, 97310F. [CrossRef]

7. Sanghera, J.S.; Shaw, L.B.; Aggarwal, I.D. Chalcogenide Glass-Fiber-Based Mid-IR Sources and Applications. IEEE J. Sel. Top. Quantum Electron. 2009, 15, 114-119. [CrossRef] 
8. Petersen, C.R.; Møller, U.; Kubat, I.; Zhou, B.; Dupont, S.; Ramsay, J.; Benson, T.; Sujecki, S.; Abdel-Moneim, N.; Tang, Z.; et al. Mid-infrared supercontinuum covering the 1.4-13.3 $\mu \mathrm{m}$ molecular fingerprint region using ultra-high NA chalcogenide step-index fibre. Nat. Photonics 2014, 8, 830-834. [CrossRef]

9. Yu, Y.; Zhang, B.; Gai, X.; Zhai, C.; Qi, S.; Guo, W.; Yang, Z.; Wang, R.; Choi, D.Y.; Madden, S.; et al. 1.8-10 $\mu \mathrm{m}$ mid-infrared supercontinuum generated in a step-index chalcogenide fiber using low peak pump power. Opt. Lett. 2015, 40, 1081. [CrossRef] [PubMed]

10. Kumar, V.V.R.K.; George, A.; Knight, J.; Russell, P. Tellurite photonic crystal fiber. Opt. Express 2003, 11, 2641. [CrossRef] [PubMed]

11. Omenetto, F.G.; Wolchover, N.A.; Wehner, M.R.; Ross, M.; Efimov, A.; Taylor, A.J.; Kumar, V.V.R.K.; George, A.K.; Knight, J.C.; Joly, N.Y.; et al. Spectrally smooth supercontinuum from $350 \mathrm{~nm}$ to $3 \mu \mathrm{m}$ in sub-centimeter lengths of soft-glass photonic crystal fibers. Opt. Express 2006, 14, 4928. [CrossRef] [PubMed]

12. Miret, J.J.; Silvestre, E.; Andrés, P. Octave-spanning ultraflat supercontinuum with soft-glass photonic crystal fibers. Opt. Express 2009, 17, 9197. [CrossRef] [PubMed]

13. Xia, C.; Kumar, M.; Kulkarni, O.P.; Islam, M.N.; Fred, L.; Terry, J.; Freeman, M.J.; Poulain, M.; Mazé, G. Mid-infrared supercontinuum generation to $4.5 \mu \mathrm{m}$ in ZBLAN fluoride fibers by nanosecond diode pumping. Opt. Lett. 2006, 31, 2553. [CrossRef] [PubMed]

14. Jiang, X.; Joly, N.Y.; Finger, M.A.; Babic, F.; Pang, M.; Sopalla, R.; Frosz, M.H.; Poulain, S.; Poulain, M.; Cardin, V.; et al. Supercontinuum generation in ZBLAN glass photonic crystal fiber with six nanobore cores. Opt. Lett. 2016, 41, 4245-4248. [CrossRef] [PubMed]

15. Zhao, Z.; Wang, X.; Dai, S.; Pan, Z.; Liu, S.; Sun, L.; Zhang, P.; Liu, Z.; Nie, Q.; Shen, X.; et al. 1.5-14 $\mu \mathrm{m}$ midinfrared supercontinuum generation in a low-loss Te-based chalcogenide step-index fiber. Opt. Lett. 2016, 41, 5222. [CrossRef] [PubMed]

16. Zhao, Z.; Wu, B.; Wang, X.; Pan, Z.; Liu, Z.; Zhang, P.; Shen, X.; Nie, Q.; Dai, S.; Wang, R. Mid-infrared supercontinuum covering 2.0-16 $\mu \mathrm{m}$ in a low-loss telluride single-mode fiber. Laser Photonics Rev. 2017, 11, 1700005. [CrossRef]

17. Domachuk, P.; Wolchover, N.A.; Cronin-Golomb, M.; Wang, A.; George, A.K.; Cordeiro, C.M.B.; Knight, J.C.; Omenetto, F.G. Over $4000 \mathrm{~nm}$ bandwidth of mid-IR supercontinuum generation in sub-centimeter segments of highly nonlinear tellurite PCFs. Opt. Express 2008, 16, 7161. [CrossRef] [PubMed]

18. Buczyński, R.; Bookey, H.; Pysz, D.; Stępień, R.; Kujawa, I.; McCarthy, J.; Waddie, A.; Kar, A.; Taghizadeh, M. Supercontinuum generation up to $2.5 \mu \mathrm{m}$ in photonic crystal fiber made of lead-bismuth-galate glass. Laser Phys. Lett. 2010, 7, 666-672. [CrossRef]

19. Zhang, W.Q.; Ebendor-Heidepriem, H.; Monro, T.M.; Afshar, V.S. Fabrication and supercontinuum generation in dispersion flattened bismuth microstructured optical fiber. Opt. Express 2011, 19, 21135. [CrossRef] [PubMed]

20. Zhang, Y.; Kainerstorfer, J.; Knight, J.C.; Omenetto, F.G. Experimental measurement of supercontinuum coherence in highly nonlinear soft-glass photonic crystal fibers. Opt. Express 2017, 25, 18842. [CrossRef] [PubMed]

21. Klimczak, M.; Siwicki, B.; Heidt, A.; Buczyński, R. Coherent supercontinuum generation in soft glass photonic crystal fibers. Photonics Res. 2017, 5, 710. [CrossRef]

22. Smektala, F.; Quemard, C.; Couderc, V.; Barthelemy, A. Non-linear optical properties of chalcogenide glasses measured by Z-scan. J. Non-Cryst. Solids 2000, 274, 232-237. [CrossRef]

23. Forestier, X.; Cimek, J.; Kujawa, I.; Kasztelanic, R.; Pysz, D.; Orliński, K.; Stępień, R.; Buczyński, R. Study of $\mathrm{SiO}_{2}-\mathrm{PbO}-\mathrm{CdO}-\mathrm{Ga}_{2} \mathrm{O}_{3}$ glass system for mid-infrared optical elements. J. Non-Cryst. Solids 2018. [CrossRef]

24. Gan, F. Optical properties of fluoride glasses: A review. J. Non-Cryst. Solids 1995, 184, 9-20. [CrossRef]

25. Rodney, W.S.; Malitson, I.H.; King, T.A. Refractive index of arsenic trisulfide. J. Opt. Soc. Am. 1958, 48, 633-635. [CrossRef]

26. Hilderbrand, S.A.; Weissleder, R. Near-infrared fluorescence: Application to in vivo molecular imaging. Curr. Opin. Chem. Biol. 2010, 14, 71-79. [CrossRef] [PubMed]

27. Choma, M.; Sarunic, M.; Yang, C.; Izatt, J. Sensitivity advantage of swept source and Fourier domain optical coherence tomography. Opt. Express 2003, 11, 2183. [CrossRef] [PubMed] 
28. Willer, U.; Saraji, M.; Khorsandi, A.; Geiser, P.; Schade, W. Near- and mid-infrared laser monitoring of industrial processes, environment and security applications. Opt. Lasers Eng. 2006, 44, 699-710. [CrossRef]

29. Lumerical Solutions, Inc. Available online: http://www.lumerical.com/tcad-products/mode/ (accessed on 24 November 2018).

30. Saitoh, K.; Koshiba, M.; Hasegawa, T.; Sasaoka, E. Chromatic dispersion control in photonic crystal fibers: Application to ultra-flattened dispersion. Opt. Express 2003, 11, 843-852. [CrossRef] [PubMed]

31. Martynkien, T.; Pysz, D.; Stępień, R.; Buczyński, R. All-solid microstructured fiber with flat normal chromatic dispersion. Opt. Lett. 2014, 39, 2342. [CrossRef] [PubMed]

32. Cimek, J.; Stępień, R.; Stępniewski, G.; Siwicki, B.; Stafiej, P.; Klimczak, M.; Pysz, D.; Buczyński, R. High contrast glasses for all-solid fibers fabrication. Opt. Mater. 2016, 62, 159-163. [CrossRef]

33. DiGiovanni, D.J.; Vengsarkar, A.M.; Wagener, J.L.; Windeler, R.S. Article Comprising a Microstructured Optical Fiber, and Method of Making Such Fiber. U.S. Patent 5,802,236, 1 September 1998.

34. Voyce, C.J.; Fitt, A.D.; Hayes, J.R.; Monro, T.M. Mathematical Modeling of the Self-Pressurizing Mechanism for Microstructured Fiber Drawing. J. Lightw. Technol. 2009, 27, 871. [CrossRef]

35. Russell, P.S.J.; Birks, T.A.; Knight, J.C. Photonic Crystal Fibres. U.S. Patent 6,888,992B2, 3 May 2005.

36. Jasion, G.T.; Shrimpton, J.S.; Chen, Y.; Bradley, T.; Richardson, D.J.; Poletti, F. MicroStructure Element Method (MSEM): Viscous flow model for the virtual draw of microstructured optical fibers. Opt. Express 2015, 23, 312-329. [CrossRef] [PubMed]

37. Stępniewski, G.; Pniewski, J.; Klimczak, M.; Martynkien, T.; Pysz, D.; Stępień, R.; Kujawa, I.; Borzycki, K.; Buczyński, R. Broadband dispersion measurement of photonic crystal fibers with nanostructured core. Opt. Quantum Electron. 2014, 47, 807-814. [CrossRef]

38. Dudley, J.M.; Genty, G.; Coen, S. Supercontinuum generation in photonic crystal fiber. Rev. Mod. Phys. 2006, 78, 1135-1184. [CrossRef]

39. Dudley, J.; Taylor, J. Supercontinuum Generation in Optical Fibers; Cambridge University Press: Cambridge, UK, 2010; p. 418.

40. Dudley, J.M.; Coen, S. Coherence properties of supercontinuum spectra generated in photonic crystal and tapered optical fibers. Opt. Lett. 2002, 27, 1180-1182. [CrossRef] [PubMed]

(C) 2018 by the authors. Licensee MDPI, Basel, Switzerland. This article is an open access article distributed under the terms and conditions of the Creative Commons Attribution (CC BY) license (http:/ / creativecommons.org/licenses/by/4.0/). 